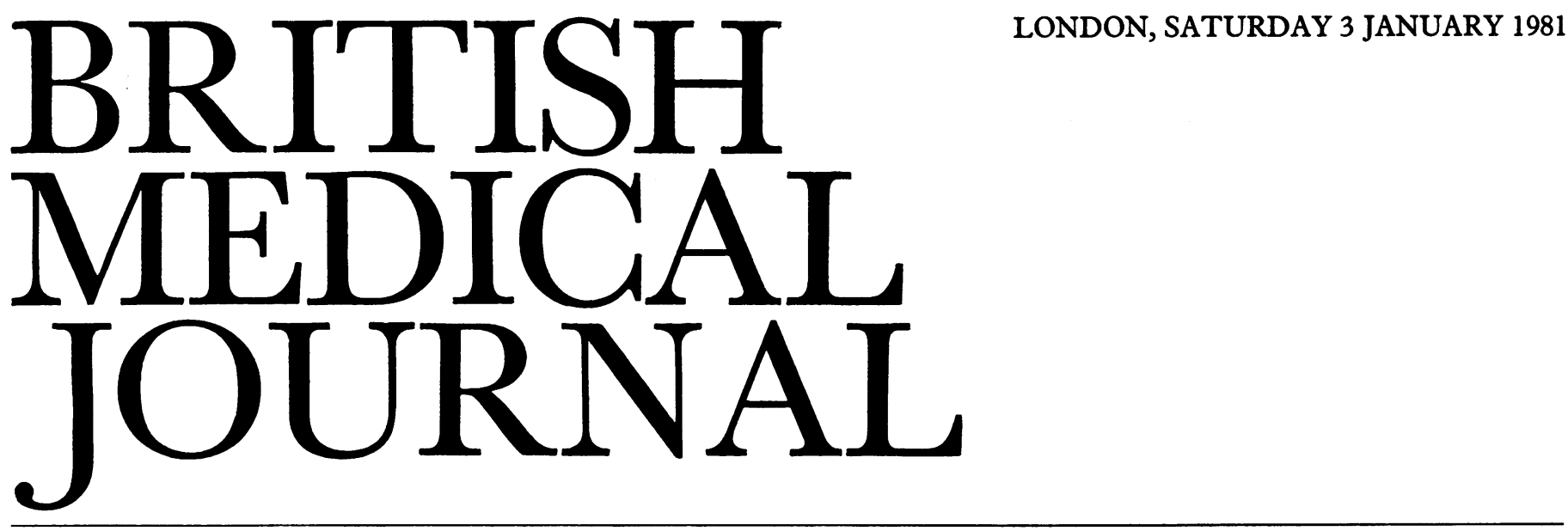

\title{
Do sick doctors need more than the GMC?
}

Schemes to deal with sick doctors must have two aims: to protect the patient and to help the sick doctor. Protecting the patient is a policing function and does not coexist easily with the caring, understanding, confidentiality, and informality needed in an effective scheme to help sick doctors. The General Medical Council's new health committee should succeed in protecting patients, but will its operation be sufficiently subtle to help all sick doctors ? Or do we also need an informal scheme that can help them at an early stage in their illness?

Until now patients have been protected by the GMC's disciplinary procedure-a blunt instrument to deal with the delicate problem of sick doctors. For hospital doctors this formal system has been complemented within the National Health Service by the "three wise men" procedure," and general practitioners have had a more formal scheme, in which local medical committees play a part. The inadequacy of the disciplinary procedure was recognised by the profession, the GMC, and the Merrison inquiry into professional regulation, ${ }^{2}$ which recommended that the GMC should set up a health committee. The Government supported the change, and the new committee has now been set up. ${ }^{3}$

With the new scheme anybody (including a patient) who is worried about a doctor's fitness to practise may write to the registrar of the GMC, who will pass the information on to the president. If the president thinks that the matter should proceed, the doctor is informed and invited to be examined by two doctors appointed by the president. These doctors will make a confidential report to the president, but the sick doctor can arrange also to be examined by other doctors, who in their turn may report to the president. If the president decides, on the basis of that advice, that the doctor is not fit to practise, or fit to practise only in certain circumstances, then he is asked to accept treatment. If he refuses he will be referred to the health committee, who have the power to suspend him.

Thus from the very beginning the registrar and the president of the GMC know about the case, records are kept, and if the complainant is a patient "sworn statements" are made. Doctors will need to be very worried about a colleague before they invoke such a system. The "three wise men" procedure is widely agreed to have failed for similar reasons: doctors came to see it as a swift and rather arbitrary system for removing incompetent doctors, not a humane way of helping their sick colleagues. So a more effective procedure is needed that can be tried before calling in the GMC. Doctors in most of the individual States in the United States have developed confidential, informal systems, ${ }^{4}$ but in Britain only one body-the
Association of Anaesthetists of Great Britain and Ireland-has succeeded in starting such a scheme.

In this scheme a doctor worried about an anaesthetist telephones the association and without having to disclose his identity is given the name and telephone number of a referee whom he can contact. The referees are all retired, distinguished anaesthetists: because they are retired they cannot influence the sick doctor's future career, and their distinction should allow them to be known to and trusted by the sick doctor. The referee will satisfy himself that a problem exists by talking to the reporting doctor and another doctor if possible. The referee will then contact a psychiatrist from another region, who will get in touch with the sick doctor. The Royal College of Psychiatrists co-operates in the scheme by providing a list of recommended psychiatrists. If the sick doctor accepts treatment then the referee destroys all records of phone numbers and names and trusts the treating psychiatrist. If after a month the sick doctor has not accepted treatment then the referee is told, and he in turn informs the original reporting doctor. There is no formal link with the GMC health committee, but the referee will make it clear to the reporting doctor that he has an ethical duty to take the matter further.

Because the scheme is highly confidential and keeps no records it is hard to know how well it is working. Nevertheless, in its two years of operation one referee (who has done most of the work) has dealt with 11 cases, and in none of them did the sick doctor refuse to accept treatment. The cases are often complicated, and people in the scheme think that the informality and flexibility allow effective intervention at a stage when the GMC scheme would be unlikely to work. Another important advantage is that an NHS doctor who goes sick will receive sick pay, whereas it appears that one who is suspended by the GMC may not under existing law, though the BMA, the GMC, and the DHSS are discussing how best to effect the necessary changes. ${ }^{3}$ The scheme is also cheap to run and is paid for by the association aided by a grant from the Medical Defence Union: the Department of Health and Social Security refused to give any financial support.

Why should only anaesthetists be able to benefit from such a scheme ? Something similar should be available to all doctors. Doctors have long been known to be as likely as any other group to develop most disabling conditions and are even more likely than the average person to become dependent on alcohol or drugs, and to kill themselves. ${ }^{5}$ Alcohol and drug dependency are the main causes of impairment in about half the doctors entering sick-doctor schemes in the United States, and these 
conditions are particularly associated with refusal to acknowledge illness-“denial." Also, sick doctors worry about losing their jobs, their status, and their incomes, and have every reason to deny their problems. The problem of denial is compounded by the "conspiracy of silence" that surrounds sick doctors, and an effective scheme for helping them is essential.

In the United States confidential and informal systems have been shown to work. One of the oldest is the Medical Association of Georgia's Disabled Doctors' Programme: after its first two years 29 of 64 disabled doctors were able to return to practice, and 20 were still in treatment. ${ }^{6}$ The non-coercive schemes that exist in most of the American States all differ from one another. When setting up a system many things have to be considered: who will run it; whom will referrals be accepted from; how will these be verified; how will the programme be publicised; how will the sick doctor be approached; what kind of treatment will be offered and where; how will the programme be financed; will records be kept; will there be a formal link with a coercive system; and how will the system be evaluated ? If it is accepted that informal and confidential schemes are needed the first question in Britain is who should organise them? Should it be the appropriate colleges, should it be the BMA, or should it be done locally ? The anaesthetists, to whom much credit is due for their initiative, are convinced that there are advantages in organising a system on a specialist basis. For one thing specialists understand best each other's problems.
The anaesthetists' scheme started only because the right people were in the right place at the right time, but sick doctors in other specialties should not be left waiting for such a chance constellation of motivation and opportunity.

There are other ways, too, of helping sick doctors: firstly, by trying to prevent the problem arising at all; and, secondly, by providing an ethical framework for dealing with the problem. Prevention must begin in medical school, and students should be given more information about the risks of alcohol dependency, drug addiction, and the emotional and professional problems that doctors encounter. As long ago as 1972 the American Medical Association House of Delegates adopted a policy that any doctor who became aware of a problem in a colleague had an ethical responsibility to do something. ${ }^{4}$ Doctors worried about a respected colleague are in a terrible dilemma, and a clear ethical declaration should make it easier for them to act. Doctors in Britain should adopt such an ethical standard.

${ }^{1}$ Ministry of Health. Prevention of harm to patients resulting from physical or mental disability of hospital medical or dental staff. London: Ministry of Health, 1960. (Circular HM (60) 45.)

2 Committee of Inquiry into the Regulation of the Medical Profession. Report. London: HMSO, 1975:111-9.

3 Anonymous. GMC Health Committee. Br Med f 1980;281 :1368.

4 Robertson JJ, ed. The impaired physician. Chicago: Department of Mental Health, American Medical Association, 1978:1.

5 Anonymous. Alcohol-dependent doctors. Br Med F 1979;ii :351.

6 Talbott GD, Richardson AC, Atkins EC. The MAG disabled doctors program : a two-year review. $\mathcal{F}$ Med Assoc $G a 1977 ; 66: 771-81$.

\section{The pacing industry}

Since the first attempts at cardiac pacing in $1952^{1}$ and eventual successful placement of an implantable pacemaker on 8 October 1958 their use has transformed the treatment of cardiac arrhythmias. Around one-third of a million patients throughout the world have had a pacemaker implanted. ${ }^{2}$ The development of implantable, self-contained, non-rechargeable power sources, the perfection of the transvenous approach, and the construction of pacemakers that can respond to the electrical activity of the heart have combined with growth in our understanding of the anatomical and electrophysiological abnormalities that cause arrhythmias to expand the indications for pacing. The sick-sinus syndrome, a term introduced in 1968 by Ferrer $^{3}$ to describe the clinical and electrocardiographic abnormalities in dysfunction of the sinus node, has now become the most frequent indication for permanent cardiac pacing. Its features range from severe persistent or episodic sinus bradycardia, sinus arrest, sinus pause, or sinoatrial block to atrioventricular junctional escape rhythms and the bradytachyarrhythmia syndrome, in which slow and rapid arrhythmias coexist.

When to implant a permanent pacemaker is not always an easy decision. Pacing is mandatory in third-degree atrioventricular block, whether the site be the atrioventricular node, the bundle of His, or distal to the bundle of His. Atrioventricular block of Mobitz type II (in which the P-R interval is fixed) is also an indication for pacing owing to the high risk of the condition progressing to complete block. The role of pacing in patients with fascicular blocks is still unresolved. At present pacing seems warranted in patients who have symptoms and who have right bundle-branch block combined with block of the superior division of the left bundle (left anterior hemiblock); right bundle-branch block combined with block of the inferior division of the left bundle branch (left posterior hemiblock); bundle-branch block associated with first-degree atrioventricular block; and alternating bundle-branch block. Some patients with frequent life-threatening refractory tachyarrhythmias that fail to respond to drugs and others with toxic side effects from drug treatment may benefit from various cardiac pacing techniques. Finally, in some patients the indications for pacing depend on data derived from His-bundle electrocardiograms, intracardiac stimulation, and mapping techniques. The value of pacing in the management of patients with the hypersensitive carotid sinus syndrome is under scrutiny; and as implantable defribrillators become available the range of indications will become even more complex.

Recently Howard Friedman and his colleagues ${ }^{4}$ have suggested that the rapid expansion of technological developments in pacing and the ready availability of devices have led to their excessive use and that the indications for pacing have been too liberally interpreted. In the United States 66723 new implants and 30025 generator replacements were carried out in 1978. During the same period in Britain, with a population about one-quarter of that of the United States, the comparable figures were 4200 and 3300.5 A reasonable balance probably lies between these extremes.

Steps have been taken to ensure that selection of patients and the fitting of pacemakers are carried out by properly trained staff in specialist centres. The European Society of Cardiology set up several working groups on cardiac pacing in 1976,6 and 25 countries now have groups or societies concerned with cardiac pacing, with good communications with the recently established International Association of Pacemaker Manufacturers. A registration card for patients 